\title{
LIMBAH PERTANIAN UNTUK PERBAIKAN KUALITAS LAHAN DAN PENINGKATAN PRODUKSI PADI SAWAH DI KECAMATAN PINANG BELAPIS KABUPATEN LEBONG
}

\section{AGRICULTURE WASTE FOR LAND QUALITY AND RICE PRODUCTIVITY IMPROVEMENT IN PINANG BELAPIS, DISTRICT OF LEBONG}

\author{
Oleh: \\ Priyono Prawito ${ }^{1)}$, Gita Mulyasari ${ }^{1)}$, Madani Hatta ${ }^{2)}$ \\ ${ }^{1)}$ Fakultas Pertanian UNIB, ${ }^{2)}$ Fakultas Ekonomi UNIB \\ Email: priyono@unib.ac.id dan prawito04@yahoo.com
}

\begin{abstract}
The people of Pinang Belapis face with the problem of declining soil quality and difficult to purchase anorganic fertilizer because of high prices and uncertain availability. The purposes of this community service are (1) to train the composting of agricultural waste materials to substitute inorganic fertilizer needs with compost and improve the quality of agricultural land by utilizing the results of composting; (2) to apply the compost to sample plots of land; (3) giving extension about the importance of organic/compost for soil and plants. Composting training is given to the boards of farmer groups. Besides composting, counseling about importance of organic fertilizer and compost in improving and maintaining soil fertility and its benefit to plants is also performed. Compost material consisting of a mixture of agricultural wastes and shrubs around the site composting is collected, chopped, and stacked layer by layer, each layer height of $20 \mathrm{~cm}$. Microbes AddCompost "Promi" is dissolved in water, and sprinkle on each layer and stacks of compacted organic material. Coating and watering is done until the compost runs out in order. Heaps of organic matter plastikagar closed with the humidity up. Compost is observed every week to measure the increase in temperature and decrease in the volume of compost. After 3 weeks, the compost is ready for harvest, as indicated by the shrinking volume of compost to about 50\%, the color changes to dark brown, crumbly brittle materials, the smell is not overpowering. Then the compost is applied to the example land plot for demonstration.
\end{abstract}

Keywords: organic material, compost, soil quality, agricultural waste, agricultural land

\section{PENDAHULUAN}

Kebutuhan beras di Indonesia akan terus meningkat dari tahun ke tahun sejalan dengan peningkatan taraf hidup masyarakat dan kemajuan industri, sehingga perlu upaya peningkatan produksi melalui pemanfaatan sumberdaya alam secara bijak, untuk menuju keberlanjutan (Zahriani, 2009). Peningkatan produktivitas usahatani padi sawah sangat dibutuhkan dalam rangka pemenuhan kebutuhan pangan rakyat Indonesia, dimana beras merupakan bahan makanan pokok masyarakat Indonesia (Mubyarto, 2002). Selama 3 
sampai 4 dekade ini teknologi pertanian yang diterapkan telah memberikan dampak negative terhadap lingkungan pada umumnya misalnya, menurunnya kualitas tanah akibat penggunaan pupuk anorganik (kimia) secara berlebihan dan terus menerus, rusaknya keseimbangan ekosistem akibat penggunaan pestisida, yang berakibat pada matinya/punahnya organisme non target (Riwandi, et al., 2012). Dengan tidak disadari pula, bahwa untuk memenuhi kebutuhan pupuk dan pestisida anorganik (kimia) memerlukan biaya yang relatif mahal, sehingga margin keuntungan petani menjadi makin kecil.

Mahalnya pupuk dan dikuranginya subsidi pupuk oleh pemerintah menjadikan petani lebih terpuruk dalam ketidakmampuan untuk memenuhi kebutuhan pupuk dalam berusahatani.Tetapi untuk menggunakan usahatani berdasarkan kearifan lokal, yaitu menggunakan pupuk organik dan pestisida organik masih belum diminati karena keterbatasan kemampuan dan pengetahuan petani dalam membuat dan mengetahui pemanfaatan pupuk dan pestisida organik dalam usahataninya.

Kecamatan Pinang Belapis berada di wilayah Kabupaten Lebong, yang sebagian besar wilayahnya merupakan kawasan Taman Nasional Kerinci Seblat (TNKS). Produk pertanian unggulan di daerah ini adalah padi sawah, dengan luas lahan untuk tanaman pangan adalah 604,9 ha. Dari segi kualitas lahan, sebagian besar lahan pertanian di Kecamatan Pinang Belapis termasuk lahan yang kurang subur. Beberapa data menunjukkan hal tersebut, misalnya $\mathrm{pH}$ tanah berkisar antara $4-4,5$ yang termasuk tanahtanah asam. Bahan organik juga rendah (rata-rata lebih kecil dari 1\%). Hasil pengamatan lapangan yang dilakukan pada saat pengabdian berlangsung menunjukkan bahwa kandungan N, P, dan K juga berkisar antara rendah - sedang (Pengamatan Lapang, 2014). Untuk mengejar target produksi yang diinginkan petani memakai pupuk anorganik yang berlebihan dengan harapan produk pertanian mereka (beras) dapat maksimal. Dalam kondisi $\mathrm{pH}$ yang rendah, dan kandiungan bahan organik juga rendah penambahan pupuk anorganik yang berlebihan tidak akan banyak menolong, karena pupuk yang diberikan akan hilang terbawa air, yang pada gilirannya akan menyebabkan pencemaran lingkungan. Seperti terlihat adanya gejala eutrofikasi di daerah-daerah cekungan yang tergenang air (Riwandi, et al., 2014).

Tingginya penggunaan jumlah pupuk anorganik menyebabkan meningkatnya keasaman tanah di lahan sawah mereka. Hal ini sejalan dengan pendapat Altieri (2000) yang mengatakan bahwa, pupuk anorganik secara temporer telah meningkatkan hasil pertanian, tetapi keuntungan hasil panen akhirnya berkurang banyak dengan adanya penggunaan pupuk ini karena adanya sesuatu yang timbul akibat adanya degradasi (pencemaran) lingkungan pada lahan pertanian.Alasan utama kenapa pupuk anorganik menimbulkan pencemaran pada tanah adalah karena dalam prakteknya banyak kandungan yang terbuang. Penggunaan pupuk buatan (anorganik) yang terus menerus akan mempercepat habisnya zat-zat organik, merusak keseimbangan zat-zat makanan di dalam 
tanah, sehingga menimbulkan peningkatan keasaman tanah dan berbagai penyakit tanaman.

Bahan organik merupakan salah satu komponen tanah yang sangat penting bagi ekosistem tanah, dimana bahan organik merupakan sumber pengikat hara dan substrat bagi mikrobia tanah. Bahan organik tanah merupakan bahan penting untuk memperbaiki kesuburan tanah, baik secara fisik, kimia, maupun biologi. Penggunaan pupuk organik dapat memperbaiki struktur tanah dan mendorong perkembangan populasi mikro organisme tanah. Aplikasi pupuk organik yang dikombinasikan dengan separuh takaran dosis standar pupuk anorganik dapat menghemat biaya pemupukan. Pengujian lapangan terhadap tanaman tanaman pangan juga menunjukkan hasil yang menggembirakan, karena dapat meningkatkan hasil produksi pertanian dan dapat menghemat biaya pempukan lahan.

Ketersediaan bahan organik di daerah pertanian padi sawah cukup berlimpah, yaitu berupa limbah jerami yang hingga saat ini tidak dimanfaatkan di daerah ini. Untuk menekan kebutuhan pupukanorganik, sekaligus memperbaiki kualitas lahan maka pemanfaatan limbah pertanian pada umumnya dan khususnya jerami pada merupakan peluang yang perlu segera mendapat perhatian.

Tujuan dari kegiatan pengabdian ini adalah untuk memberikan gambaran akan pentingnya bahan organik bagi perbaikan atau menjada kualitas lahan, serta fungsi bahan organik sebagai penyedia unsur hara untuk mensubstitusi atau menekan kebutuhan pupuk anorgani. Selain itu dalam kegiatan pengabdian ini juga akan diberikan pengetahuan untuk melakukan pengomposan limbah pertanian agar limbah tersebut dapat digunakan untuk menambah bahan organik tanah tanpa mengganggu pertumbuhan tanaman yang diusahakan.

Kegiatan ini diharapkan dapat memberikan pengetahuan tambahan dalam hal manfaat dan fungsi bahan organik bagi tanah dan tumbuhan. Selain pengetahuan, kegiatan ini juga diharapkan dapat memberikan skill tambahan terhadap petani dalam hal pengomposan limbah pertanian untuk pupuk organik.

\section{METODE PENGABDIAN}

Untuk mengatasi permasalahan yang dihadapi oleh petani padi di Kecamatan Pinang Belapis Kabupaten Lebong diperlukan suatu solusi yang dapat membantu petani dalam memenuhi kebutuhan pupuk usahataninya. Permasalahan yang dihadapi sebenarnya dapat diatasi oleh petani sendiri apabila petani mendapat bekal pengetahuan dan keterampilan melalui pengenalterapan teknologi. Teknologi yang diperkenalkan dapat dengan mudah diterima dan diterapkan oleh masyarakat, terutama petani karena secara ekonomis, teknis, sosial, budaya dan lingkungan layak dikembangkan.

Langkah-langkah yang dilakukan dalam pengabdian ini adalah dengan penyuluhan dan pelatihan. Untuk kegiatan penyuluhan, petani padi diberikan sosialisasi mengenai pupuk organik, manfaat dari pupuk organik, dan cara pembuatan pupuk organik dengan memanfaatkan limbah pertanian yang ada di sekitar lahan mereka. Kecamatan Pinang 
Belapis. Kegiatan sosialisasi dan penyuluhan ini melibatkan para pengurus kelompok tani, dan melibatkan para penyuluh dari BP3K Ketenong Jaya sebagai fasilitator dan mitra dalam kegiatan pengabdian ini.

Kegiatan selanjutnya adalah praktek pembuatan pupuk organik yang tetap melibatkan petani padi di Kecamatan Pinang Belapis Kabupaten Lebong. Tim Pengabdian bekerja sama dengan petani dan BP3K mengumpulkan berbagai limbah pertanian yang terdapat di sekitar lokasi pengabdian yang kemudian diolah menjadi pupuk organik. Pembuatan pupuk organik ini diharapkan nantinya dapat dilakukan secara mandiri oleh petani padi, sehingga permasalahan ketidaksuburan lahan sawah mereka dapat teratasi dan meningkatkan produktivitas usahataninya.

\section{HASIL DAN PEMBAHASAN}

Langkah awal yang dilakukan Tim adalah FGD (focus group discussion) yang dilakukan untuk mensosialisasikan kembali kegiatan yang telah kita rancang sebelumnya (bersama beberapa tokoh masyarakat, dan penyulu BP3K) kepada masyarakat yang lebih luas yaitu pengurus kelompok tahi di wilayah Kecamatan Pinang Belapis. Selain sosialisasi, dalam diskusi ini juga dilakukan need assessment, untuk memetakan masalah mereka berikut menentukan kegiatan yang akan kita pilih untuk menyelesaikan sebagaian masalah yang mereka hadapi. Dalam hal ini mengerucut pada pemanfaatan limbah pertanian untuk pupuk organik. Dalam diskusi ini juga disepakati agenda selama pengabdian pada masyarakat yang berkaitan dengan penyuluhan dan pelatihan pembuatan kompos. Materi penyuluhan dan materi pelatihan disepakati dalam pertemuan ini. Berikut adalah susunan rencana kegiatan penyuluhan dan pelatihan pembuatan kompos (Tabel 1).

Pada saat berlangsung FGD, selain memlakukan pemetaan masalah dan menyusun jadwal kegiatan, diskusi juga berlangsung pada hal-hal yang sustantif yang berkaitan dengan persoalan kemerosotan kualitas lahan mereka. Dalam diskusi ini pada akhirnya ditemukan bahwa solusi yang secara social diterima, secara ekonomi murah, dan secara ekologis ramah, adalah pemanfaatan limbah pertanian untuk dijadikan pupuk organik. Persoalannya adalah bahwa tidak semua bahan organik dapat segera digunakan untuk pupuk karena nilai $\mathrm{C} / \mathrm{N}$ rasio tinggi (>30). Kenyataanya bahkan sebaliknya, justru sebagian besar limbah pertanian dan bahan-bahan yang tersedia disekitar lahan mereka bukan bahan organik yang dapat segera dipakai. Agar bahan organik limbah pertanian dan yang tersedia disekitar lahan mereka dapat dipakai perlu perlakuan khuss yaitu pengomposan, agar rasii C/N turun mendekati angka 12. 
Tabel 1. Kesepakatan Jadwal kegiatan Pengabdian pada masyarakat di Kecamatan Pinang Belapis tahun 2014

\begin{tabular}{|c|c|c|c|c|}
\hline $\begin{array}{l}\text { Waktu } \\
\text { (WIB) }\end{array}$ & Kegiatan & Peserta & Tempat & $\begin{array}{c}\text { Fasilitator/ } \\
\text { Penanggung } \\
\text { Jawab }\end{array}$ \\
\hline \multicolumn{5}{|c|}{16 September 2014} \\
\hline $\begin{array}{c}15.30- \\
17.30\end{array}$ & $\begin{array}{ll}\text { 1. } & \text { FGD. Need } \\
& \text { Assesment dan } \\
& \text { Pemetaan masalah } \\
\text { 2. } & \text { Penyuluhan : Bahan } \\
\text { organik, Tanah dan } \\
\text { Tanaman padi }\end{array}$ & $\begin{array}{l}\text { Pengurus Kel. Tani } \\
\text { dan Penyuluh } \\
\text { BP3K }\end{array}$ & Aula BP3K & Priyono Prawito \\
\hline \multicolumn{5}{|c|}{30 September 2014} \\
\hline $\begin{array}{c}15.30- \\
17.30\end{array}$ & $\begin{array}{l}\text { Penyuluhan : } \\
\text { Kompos dan } \\
\text { Pengomposan }\end{array}$ & $\begin{array}{l}\text { Pengurus Kel. Tani } \\
\text { dan Penyuluh } \\
\text { BP3K }\end{array}$ & Aula BP3K & Priyono Prawito \\
\hline \multicolumn{5}{|c|}{1 Oktober 2014} \\
\hline $\begin{array}{l}09.00- \\
11.30\end{array}$ & $\begin{array}{l}\text { Praktek Pembuatan } \\
\text { Kompos }\end{array}$ & $\begin{array}{l}\text { Pengurus Kel. Tani } \\
\text { dan Penyuluh } \\
\text { BP3K }\end{array}$ & $\begin{array}{l}\text { Halaman } \\
\text { Belakang } \\
\text { BP3K }\end{array}$ & $\begin{array}{l}\text { Tim Lengkap } \\
\text { (Priyono, Gita, } \\
\text { Hatta, dan Oma) }\end{array}$ \\
\hline $\begin{array}{c}12.00- \\
13.00\end{array}$ & Istirahat Makan siang & $\begin{array}{l}\text { Pengurus Kel. Tani } \\
\text { dan Penyuluh } \\
\text { BP3K, dan Tim } \\
\text { UNIB }\end{array}$ & Aula BP3K & $\begin{array}{l}\text { BP3K (Oma } \\
\text { dkk) }\end{array}$ \\
\hline $\begin{array}{c}13.30- \\
15.00\end{array}$ & $\begin{array}{l}\text { Penyusunan Modul/Buku } \\
\text { saku Teknik Pembuatan } \\
\text { Kompos }\end{array}$ & $\begin{array}{l}\text { Pengurus Kel. Tani } \\
\text { dan Penyuluh } \\
\text { BP3K }\end{array}$ & Aula BP3K & Priyono Prawito \\
\hline \multicolumn{5}{|c|}{8 Oktober 2014} \\
\hline $\begin{array}{l}09.00- \\
10.00\end{array}$ & Monitoring Pengomposan & $\begin{array}{l}\text { BP3K dan } \\
\text { masyarakat sekitar }\end{array}$ & $\begin{array}{l}\text { Halaman } \\
\text { Belakang } \\
\text { BP3K }\end{array}$ & BP3K (Oma) \\
\hline \multicolumn{5}{|c|}{15 Oktober 2014} \\
\hline $\begin{array}{l}09.00- \\
10.00\end{array}$ & Monitoring Pengomposan & $\begin{array}{l}\text { BP3K dan } \\
\text { masyarakat sekitar }\end{array}$ & $\begin{array}{l}\text { Halaman } \\
\text { Belakang } \\
\text { BP3K } \\
\end{array}$ & BP3K (Oma) \\
\hline \multicolumn{5}{|c|}{22 Okt. 2014} \\
\hline $\begin{array}{l}09.00- \\
11.00\end{array}$ & $\begin{array}{l}\text { Monitoring dan Panen } \\
\text { Kompos }\end{array}$ & $\begin{array}{l}\text { BP3K dan } \\
\text { Masyarakat sekitar }\end{array}$ & $\begin{array}{l}\text { Halaman } \\
\text { Belakang } \\
\text { BP3K }\end{array}$ & $\begin{array}{l}\text { Tim Lengkap } \\
\text { (Priyono, Gita, } \\
\text { Hatta, dan Oma) }\end{array}$ \\
\hline $\begin{array}{c}11.00- \\
12.00\end{array}$ & $\begin{array}{l}\text { Praktek Pengambilan } \\
\text { sampel tanah }\end{array}$ & Penyuluh BP3K & $\begin{array}{l}\text { Lahan sawah } \\
\text { milik BP3K }\end{array}$ & $\begin{array}{l}\text { Tim Lengkap } \\
\text { (Priyono, Gita, } \\
\text { Hatta, dan Oma) }\end{array}$ \\
\hline $\begin{array}{c}12.00- \\
13.00\end{array}$ & $\begin{array}{l}\text { Praktek analisa contoh } \\
\text { tanah }\end{array}$ & Penyuluh BP3K & $\begin{array}{l}\text { Teras depan } \\
\text { BP3K }\end{array}$ & $\begin{array}{l}\text { Tim Lengkap } \\
\text { (Priyono, Gita } \\
\text { dan Hatta) }\end{array}$ \\
\hline
\end{tabular}

Pada pertemuan pertama ini kemudian disepakati untuk bertemu lagi pada 2 minggu berikutnya yaitu tanggal 30 September 2014, siang/sore hari untuk bertemu lagi membicarakan teknik pengomposan dan berbagai hal yang berkaitan dengan kompos dan pengomposan. Pada saat pertemuan ini juga disepakati pada tanggal 1 Oktober 2014 pagi hari, jam 09.00 WIB dilakukan praktek pembuatan kompos. Dengan masing-masing tugas, 
Tim UNIB membawa peralatan dan bahan mikro organisme, sedang BP3K menyiapkan tempat, serta masyarakat menyiapkan bahan yang akan dikomposkan berupa jerami dan bahan organik hijau seperti semak dan rumput-rumputan sebanyak kurang lebih $500 \mathrm{~kg}$. Beberapa foto kegiatan penyuluhan dan pelatihan pembuatan kompos disajikan dalam (Gambar 1 dan 2).
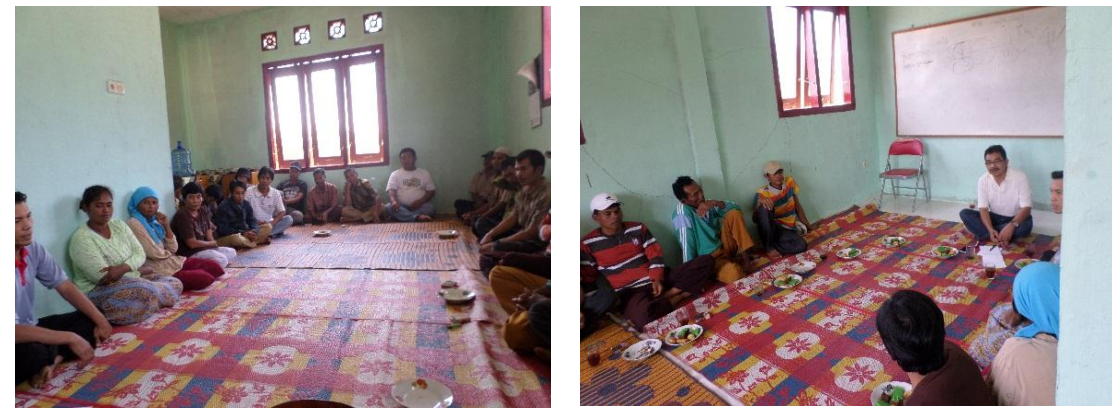

Gambar 1. Suasana FGD dan keadaan rumah kompos yang ada di Desa Ketenong, Kecamatan Pinang Belapis Kabupaten Lebong tahun 2014.
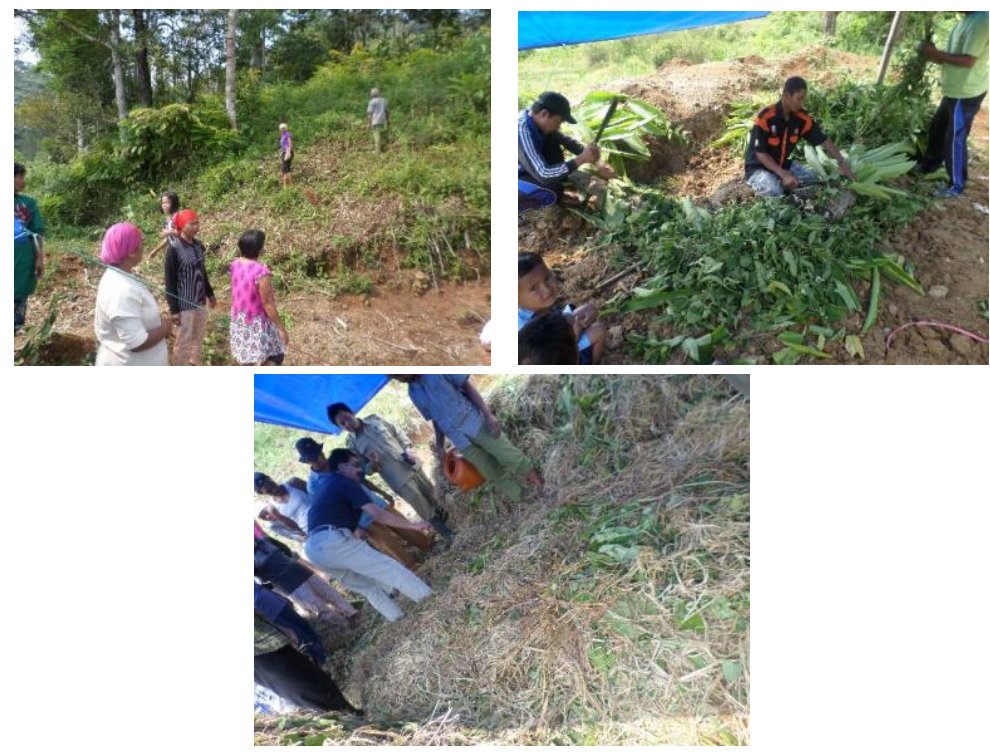

Gambar 2. Kegiatan pelatihan pembuatan kompos di Kecamatan Pinang Belapis Kabupaten Lebong tahun 2014.

Sebagaimana disepakati pada saat pertemuan awal, penuluhan dilakukan pada tanggal 30 September sore hari dengan materi penyuluhan berupa dasar teoritis tentang pentingnya bahan organik bagi kesuburan tanah dan pertumbuhan tanaman. Dasar teori ini sengaja diberikan agar petani memiliki pemahaman akan pentingnya bahan organik bagi tanah dan tanaman. Cara penyampaian materi sengaja dilakukan dengan cara diskusi, sedang Tim UNIB hanya berfundsi sebagai fasilitator. Pilihan metode ini agar peserta penyuluhan tidak merasa bosan karena mereka aktif berdiskusi. 
Pada tanggal 1 Oktober 2014 jam 09.00 WIB adalah acara pelatihan pembuatan kompos. Sesuai dengan kesepakatan awal masing-masing stake holder memiliki tugas dan kewajiban masing-masing. Tim UNIB menyiapkan berbagai peralatan yang dibutuhkan, yang belum ada di lokasi seperti plasti, terpal, gembor, dan mikro organisme perombak. Disediakan EM4 untuk mewakili mikroorganisme dalam proses pengomposan yang anaerob, dan Promi untuk mewakili mikro organisme yang digunakan dalam pengomposan yang aerob. Pemilihan itu semata-mata haya yang paling mudah dicari dipasaran sekitar lokasi pengabdian. BP3K telah menyapkan lokasi, sedang masyarakat bergotongroyong mengumpulkan bahan organik (limbah pertanian). Karena pada saat pelaksanaan pelatihan tidak bertepatan dengan musim panen padi maka jerami terpaksa didatangkan dari daerah di luar Pinang Belapis (Gambar 3).
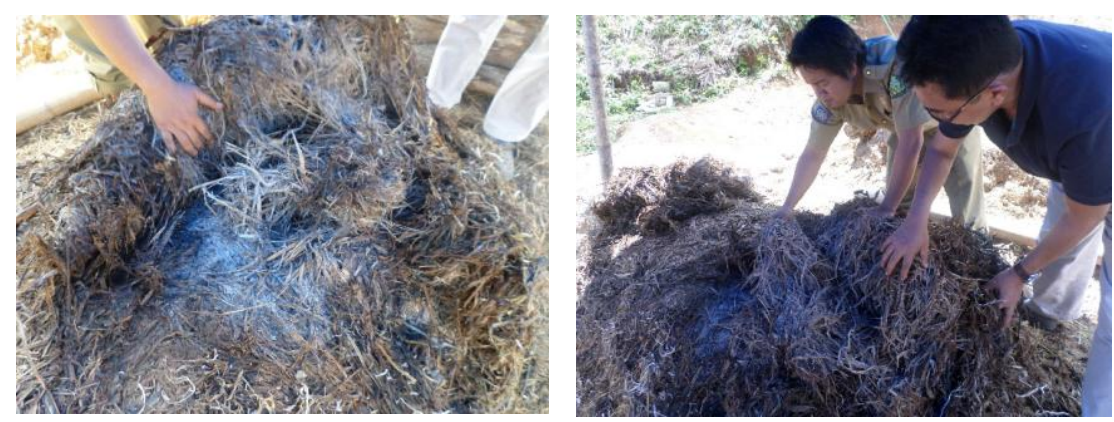

Gambar 3. Keadaan kompos pada akhir minggu ke-3 dalam kegiatan pengabdian di Kecamatan Pinang Belapis Kabupaten Lebong tahun 2014

Setelah selesai kegiatan pelatihan, dan istirahat makan siang, masyarakat berkumpul lagi untuk menyusun buku panduan, atau buku saku tentang cara membuat kompos yang sederhana. Pada dasarnya mereka difasilitasi untuk mendokumentasikan apa yang telah mereka kerjakan agar tidak hilang begitu saja. Dan ada kemungkinan orang lain yang tidak hadir dalam pertemuan ini dapat melakukan hal yang sama dengan membaca buku saku yang mereka buat.

Kegiatan monitoring tehadap proses pembuatan kompos dilakukan secara rutin, tiap minggu sekali dengan mengamati volume tumpukan kompos, suhu dan kelembapan kompos. Pada akhir minggu pertama terjadi kenaikan suhu tumpukan kompos sampai sekitar $40{ }^{\circ} \mathrm{C}$, sementara volume kompos belum mengalami perubahan. Seperti halnya volume kompos, kelembaban kompos juga tidak banyak berubah (mengering) karena kompos ditutup rapat dengan plastic sehingga penguapan kompos dapat ditekan dan kelembaban dapat terjaga dengan baik. Suhu kompos yang sekitar $40{ }^{\circ} \mathrm{C}$ ini terus dijaga dan diamati lebih sering kalau terjadi peningkatan suhu yang berlebihan. Hingga akhir minggu ke dua suhu tetap bertahan sekitar $40{ }^{\circ} \mathrm{C}$ dan kompos dibiarkan tertutup tanpa dilakukan pembalikan. Pada minggu kedua ini volume kompos sudah turun sekitar $50 \%$ mengindikasikan bahwa proses pembuatan kompos berjalan dengan baik. Kelembaban tetap terhjaga, sehingga tidak dilakukan penambahan iar atau penyiraman. Secara fisik 
pada pengamatan minggu ke tiga ini selain telah terjadi penyusutan volume, juga terjadi perubahan warna yang telah berubah menjadi coklat kehitaman, merupakan tanda bahwa pengomposan berjalan dengan baik. Selain warna, bahan organik juga sangat rapuh dan mudah hancur, meskipun bentuk asal daun dan ranting masih dapat dikenali.

Pengamatan pada minggu ketiga menemukan bahwa suhu kompos telah menurun hingga sekitar $30-35{ }^{\circ} \mathrm{C}$, demikian juga volume kompos telah menyusut mencapai lebih dari $50 \%$ dari volume awal. Secara fisik telah terjadi berubahan yang menunjukkan bahwa proses pembuatan kompos telah berjalan dengan baik dan kompos telah siap dipanen. Beberapa indikator yang menunjukkan kompos telah siap panen adalah warna yang telah berubah menjadi coklat kehitaman atau hitam kecoklatan, bahan organik telah rapuh dan hancur sebagian bahan organik tidak dapat dikenali lagi bahan asalnya, dan bau kompos tidak tajam.

Kegiatan dilanjutkan dengan pelatihan terhadap tenaga penyuluh pertanian di BP3K Kecamatan Pinang Belapis untuk menentukan kualitas tanah secara cepat dengan soil test kit yang telah ada. Pelatihan diawali dengan menentukan titik pengambilan sampel dari areal persawahan yang akan ditentukan kualitas tanahnya. Dilanjutkan dengan pengambilan sampel tanah dan menganalisis tanah dengan peralatan yang telah tersedia. Dari analisis ini dapat diketahui status unsur hara Nitrogen, Phosphor, dan Kalium. Kandungan $\mathrm{N}$ tanah termasuk rendah sampai sedang. Sedang kadar P dan K termasuk rendah. Demikian juga pH tanah termasuk dalam kelas asam (Gambar 4).
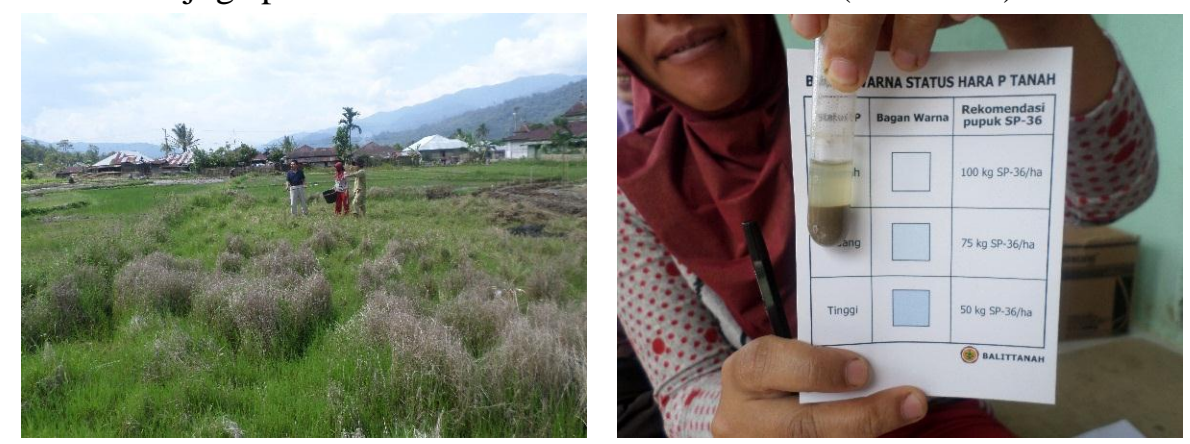

Gambar 4. Pelatihan penentuan kualitas tanah dalam kegiatan pengabdian masyarakat di

Kecamatan Pinang belapis Kabupaten Lebong tahun 2014

Dalam pelatihan ini selain praktek memanfaatkan Soil Test Kit yang ada, juga dilakukan diskusi untuk menggali berbagai pengetahuan yang berkaitan dengan sifat-sifat fisik, kimia dan biologi tanah yang berkaitan dengan pelatihan ini. Diharapkan diskusi ini dapat menambah wawasan dan pengetahuan bagi para penyuluh khususnya terhadap berbagai hal yang berkaitan dengan lahan sawah. Dengan dipahaminya teori yang ada yang berkaitan dengan lahan sawah dan budidaya padi sawah, diharapkan para penyuluh makin confidence menghadapi petani, dan dapat menjelaskan dengan baik apabila ada pertanyaan petani yang berkaitan dengan budidaya pada sawah mereka. Karena kegiatan utama dalam pengabdian ini adalah pemanfaatan kompos, maka cara untuk mengkonversi kebutuhan 
unsur tertentu seperti $\mathrm{N}, \mathrm{P}$, atau $\mathrm{K}$ terhadap jumlah pupuk organik yang diperlukan juga dilakukan.

Sebagaimana direncanakan sejak awal kegiatan pengabdian ini, bahwa salah satu tujuan kegiatan pembuatan kompos ini adalah untuk menekan kebutuhan pupuk anorganik bagi lahan sawah di Kecamatan Pinang Belapis, Kabupaten Lebong. Kegiatan ini bekerjasama dengan para penyuluh Pertanian di Desa Ketenong Jaya dimana kantor penyuluh pertanian (BP3K) berada. Tindak lanjut dari pelatihan pembuatan kompos ini adalah mendorong masyarakat secara luas melakukan pembuatan kompos dan mengaplikasikannya di lahan sawah mereka. Untuk kegiatan ini Para penyuluh pertanian di kecamatan ini akan bertanggung jawab untuk melakukan atau menyebarkan ke masyarakat di wilayah Pinang Belapis khususnya atau Kabupaten Lebong pada umumnya. Sebagai langkah awal, bersama-sama dengan para penyuluh pertanian di wilayah ini, Tim UNIB melakukan demonstrasi plot, pemanfaatan kompos pada lahan sawah. Lokasi Demplot ini adalah lahan milik BP3K yang berada di Desa Ketenong Jaya, dengan luas sekitar 1 ha.

\section{KESIMPULAN DAN SARAN}

\section{Kesimpulan}

Beberapa hal menarik dari hasil pengabdian ini layak dikemukakan dalam bab ini. Karena dari kegiatan pengabdian ini terbuka kenyataan bahwa masyarakat yang belakangan ini dianggap sangat pragmatis, tidak jujur, malas dan oportunis ternyata tidak terlihat di desa-desa wilayah Kecamatan Pinang Belapis, dimana kegiatan pengabdian ini dilakukan. Perguruan tinggi sebagai sumber ilmu pengetahuan, sebaiknya secara terbuka mau memberi dan menerima ilmu pengetahuan untuk dan dari masyarakat sekalipun. Karena banyak kearifan local yang tersimpan di masyarakat kadang-kadang dapat menjadi sumber penyelesaian masalah mereka. Dengan memfasilitasi masyarakat untuk menggali potensi yang ada di masyarakat tidak mustahil masyarakat dapat menyelesaikan masalah mereka dengan sumberdaya yang mereka miliki.

Hanya dengan memberi pengetahuan tentang manfaat bahan organik bagi tanah dan tanaman baik padi maupun tanaman palawija, serta cara pengomposan, petani akan menyadari adanya potensi untuk mengatasi permasalahan lahan sawah mereka. Hingga pengabdian ini selesai dilakukan, masyarakat secara antusias terus mengikuti seluruh kegiatan yang telah disepakati. Beberapa indikasi bahwa kegiatan ini menyentuh kebutuhan mereka adalah adanya rencana kelompok ibu-ibu yang telah memulai pembuatan kompos dengan bahan organik yang ada di sekitar mereka untuk keperluan penanaman sayur di sekitar tempat tinggal mereka. Untuk kelompok tani (kelompok bapak-bapak) akan memanfaatkan limbah pertanian khususnya jerami untuk dikembalikan ke lahan mereka dengan terlebih dahulu dikomposkan di dalam lahan dari mana bahan tersebut berasal.

Kegiatan pengabdian ini diikuti sekitar 25 - 30 orang pengurus kelompok tani dari 5 desa di wilayak Kecamatan Pinang Belapis. Sebagian besar mereka adalah ketua dan 
pengurus kelompok tani dan sebagian adalah masyarakat tani disekitar kantor BP3K Desa Ketenong Jaya.

\section{Saran}

Untuk menjaga konsistensi masyarakat perlu terus dibangun komunikasi dengan mereka. Komunikasi ini selain untuk menjaga keberlangsungan kegiatan pengabdian ini juga untuk terus memberikan kesempatan pada petani agar akses pada Perguruan Tinggi atau BP3K terus terjaga, sehingga apabila petani menghadapi masalah dapat dikomunikasikan dan dicarikan solusi bersama-sama.

\section{DAFTAR PUSTAKA}

Altieri, M.A., 2000, Sustainable Agriculture Extension Manual, UNDP SANE (Sustainable Agriculture Networking and Extension) Program, California.

Mubyarto, 2002, Pengantar Ekonomi Pertanian, Edisi Ketiga, LP3ES, Jakarta.

Riwandi, M., Handajaningsih, dan Hasanudin, 2012, Teknologi Tepat Guna Pupuk Kompos dan Teknologi Pembuatannya, UNIB Press, LPPM UNIB, Bengkulu.

Riwandi, M., Handajaningsih, dan Hasanudin, 2014, Teknik Budidaya Jagung dengan Sistem Organik di Lahan Marjinal, UNIB Press, LPPM UNIB, Bengkulu.

Zahriani, P., 2009, Pembangunan Pertanian di Era Globalisasi, Penerbit PT. Pelita Harapan, Jakarta. 